\title{
Exploring the effect of problem based facilitatory teaching approach on motivation to learn: a quasi-experimental study of nursing students in Tanzania
}

\author{
Walter C. Millanzi ${ }^{*}$ (D) and S. M. Kibusi
}

\begin{abstract}
Background: Academic motivation is most important as a key determinant of competent and motivated nurses who are often considered as frontline healthcare providers who devote most of their time taking care of clients and patients. However, most of them demonstrate remarkable differences in their academic performances during their schooling that might be due to the differences in their academic motivation and achievement motivation. There appears a growing concern to rethink the approaches on how nurses are prepared, explore, and test novel approaches for delivering the nursing curricula. This study tested the effect of Problem Based Facilitatory Teaching pedagogy on academic motivation among nursing students in Tanzania, higher learning institutions.

Methods: A pre-post-test controlled quasi-experimental study of 401 purposively selected participants was conducted between February and June 2018. The study was not a clinical randomized controlled trial and thus it has not been identified in the title and no summary of trial design, its methods, results, and conclusion. The Auditing Inventory developed by the researcher measured the intervention and a Questionnaire titled "Academic Motivation Scale," was adopted to measure academic motivation. Statistical Product for Service Solutions software program version 23 was used to perform descriptive analysis to establish participants' sociodemographic profiles. Regression analysis was performed to determine the association between variables.

Results: Findings revealed that $65.8 \%$ of participants were males. Post-test findings showed $70.3 \%$ of participants demonstrated the motive to learn contrary to $34.9 \%$ at baseline. The odds of an intervention to influence academic motivation among participants was higher than the control ( $\mathrm{AOR}=1.720 ; p<0.05 ; 95 \% \mathrm{Cl}$ : 1.122, 2.635). However, the intervention demonstrated little influence on the extrinsic motivation to learn ( $\mathrm{AOR}=0.676, p>0.05,95 \% \mathrm{Cl}$ : $0.405,1.129)$ and Amotivation to learn ( $\mathrm{AOR}=0.538, p>0.05 ; 95 \% \mathrm{Cl}: 0.283,1.022)$ compared to the control.

Conclusion: The Problem Based Facilitatory Teaching pedagogy was a predictive factor to intrinsic academic motivation among nursing students. The approach demonstrated educational potentials to change the spectrum of nursing competency and quality of care to patients or clients. This study suggests problem-based facilitatory teaching pedagogy be integrated into the nursing curriculum in Tanzania as it is feasible.
\end{abstract}

Keywords: Motivation, Problem-based, Learning, Facilitator, Teaching, Nursing, Pedagogy, Education, Medical, And curriculum

\footnotetext{
*Correspondence: wcleo87@outlook.com; walter.millanzi@udom.ac.tz

Department of Nursing Management and Education, School of Nursing and

Public Health, The University of Dodoma (UDOM), Dodoma, Tanzania
}

(c) The Author(s). 2021 Open Access This article is licensed under a Creative Commons Attribution 4.0 International License, which permits use, sharing, adaptation, distribution and reproduction in any medium or format, as long as you give appropriate credit to the original author(s) and the source, provide a link to the Creative Commons licence, and indicate if changes were made. The images or other third party material in this article are included in the article's Creative Commons licence, unless indicated otherwise in a credit line to the material. If material is not included in the article's Creative Commons licence and your intended use is not permitted by statutory regulation or exceeds the permitted use, you will need to obtain permission directly from the copyright holder. To view a copy of this licence, visit http://creativecommons.org/licenses/by/4.0/ The Creative Commons Public Domain Dedication waiver (http://creativecommons.org/publicdomain/zero/1.0/) applies to the data made available in this article, unless otherwise stated in a credit line to the data. 


\section{Contribution to the Literature}

- Findings of this study enlighten the professional associations as welfare organs about the existing pedagogical gaps demonstrated by the lecture-based learning approach on motivating nursing students to learn so that its alternative problem based facilitatory pedagogy be incorporated and implemented in the nursing curriculum among Tanzanian higher training institutions

- Moreover, the findings of the study give light to program and curriculum developers about the importance of developing programs and curriculum in the nature of problem-based facilitatory pedagogy that emphasizes collaborative learning to promote nursing students' motivation to learn. By so doing, it might ensure the production of the motivated nursing graduate who will be able to work independently in an ethical manner when providing health care services among people.

- Findings establish a vital knowledge that informs instructors on how to design and implement nursing curriculum courses in the nature of problem-based facilitatory pedagogy to promote nursing students' motivation to learn and be interested in nursing programs.

- Researchers will also use the findings of this study as baseline data for further interventional studies and or projects.

\section{Background}

Nurses are often considered as frontline healthcare providers who devote most of their time taking care of clients and patients [1]. Academic motivation is most important as a key determinant of competent and motivated nurses who are often considered as frontline healthcare providers who devote most of their time taking care of clients and patients [2]. However, most of them demonstrate remarkable differences in their academic performances during their schooling that might be due to the differences in their academic motivation and achievement motivation [3]. Nursing students' differences in their academic and achievement motivation have been associated with the unethical and illegal practices, under standard care and malpractice they demonstrate in clinical settings when providing care to patients or clients [4].

Educators and other stakeholders in nursing education link unethical, illegal, and malpractices among nurses with the inadequate and improper nurse preparations in low and higher nursing training institutions, which are the potential academic environment to improve their academic motivation and achievement motivation [5]. Millanzi et al., [4] uncovered that recent changes in nursing education and the community and stakeholders' concerns about the quality of nursing care expected from competent nurses have led to the desire to rethink and provide meaningful teaching and learning, which motivates students to learn with minimal support from instructors. Motivation to learn is a measure of nursing competence, which indicates that professional nurses are prepared to resolve nursing problems in a rapidly changing environment [6].

Carroll [7] described the academic motivation and academic achievements to be two significant factors in the analysis of academic performance for students. Academic motivation refers to a student's inner desire that guides behavior towards learning and academic achievements influenced by both, internal and external factors. Moreover, Khamoushi et al., [8] defined academic motivation as a learner's internal aspiration towards learning and academic achievements that can be influenced by both internal factors such as interest, reasons, or goals and external factors such as rewards, punishment, or material gain. This study believed that motivation plays a major role in explaining behaviors, predicting the effects of actions, and guiding behavior to achieve objectives.

Academic motivation does not only promote learning but also an intermediate impact on learning which helps students to have smooth relationships, decrease stress, increase creativity, and promote open learning [9]. Various scholars define academic motivation as the required stimulation to do the assignments, to achieve the goals, or to acquire a certain degree of competence in one's work and consequently gain academic achievements [5, $10,11]$. It is a key factor in a student's academic performance in a problem-based environment. Academic motivation can be classified as intrinsic motivation (to know), intrinsic motivation (toward accomplishment), intrinsic motivation (to experience motivation), extrinsic motivation (Identified), extrinsic motivation (Introjected), extrinsic motivation (External regulation), and Amotivation to learn.

Motivating nursing students to learn is an essential component to ensure competent graduates who can exhibit safe, ethical, and legal practice as a backbone and critical issue in the nursing education field $[5,10,12]$. The importance of motivating nursing students to learn has also been pinpointed by scholars such as Duiker [6] who found out that nursing student can demonstrate ethical and legal professional conducts when are wellformed in a well and organized motivating learning environment. The reviewed pieces of literature unfold that students' motivation in education is often driven by two questions "Can I do this task?" (Beliefs on one's capabilities, factors that cause success, and one's low influence on success). Moreover, questions such as "Why am I 
doing this task?" (Task values-interestingness, importance, utility, goal orientation) can drive students' motivation to learn.

The curricula in nursing institutions are challenged to motivate nursing students to acquire appropriate skills that will allow them to offer high-quality care to patients/clients through safe, ethical, and legal practices [13]. Challenges are still visible particularly on enhancing student's intrinsic motivation (to know), intrinsic motivation (toward accomplishment), and intrinsic motivation (to experience motivation). Some literature acknowledges that the existing pedagogical approaches including the lecture method to have demonstrated remarkable contributions to improving extrinsic motivation (Identified), extrinsic motivation (Introjected), extrinsic motivation (External regulation), and Amotivation to learn among nursing students.

Some global initiatives including the introduction of competency-based curricula in nursing are being practiced to address the existing content and pedagogical gaps. Tanzania is among Sub-Saharan African countries that adopted competency-based curricula. However, no evidence shows how Health Science Colleges/Universities have changed to cater to new demands $[1,14]$. Tutors and lecturers, still focus on developing course contents along with traditional instructional-based pedagogies with the hope that learners will be motivated and automatically develop the intended knowledge and skills $[4,15]$. Educators find themselves utilize instructional teaching methods (traditional) more often because it is cheap, easy to implement, can cover an extensive course content at once, and suitable for a large group of students [16]. Moreover, some tutors and or lecturers are not well prepared and guided by formal pedagogical guidelines to enhance learning processes among students. Most of them demonstrated teaching skills in the way they were taught when they were students than the way educational requirements recommend them to practice. Likewise, students are trained in such a way they associate teaching and learning as the process, which involves preparing for a test or earning a grade [8].

However, scholars have noted that competency-based curricula aligned with facilitation in the problem-based environment, has been seen to be a robust educational solution $[1,4,17]$. PBL is a teaching pedagogy that uses real-world problems as the motivator of student's selfdirected learning [18]. The approach has an emphasis on academic motivation and knowledge construction rather than knowledge transmission [19]. Vygotsky [20] uncovered that students can build up new knowledge from their existing one (zonal of proximal development) while scaffolding being the support strategy to help them achieve their significant developmental potentials. Students exposed to the PBL are given opportunities to explore, investigate, analyze, synthesize, and carry out experiments and eventually reach their conclusions while the instructor's roles are just to facilitate, direct, guide, and assist students to learn [21].

All the same, the PBL pedagogy requires instructors to play a role of posing questions to the entire class, and assign students to work in teams, and reach an agreement on their answers, which then they share in the entire class [1, 22, 23]. However, what is lacking is to understand how can problem-based facilitatory pedagogy be designed, implemented, and work in lowresource countries such as Tanzania in improving academic motivation among nursing students [17]. There are scarce scholarly works about the subject in Tanzania because little has been done to demonstrate the means through which Tanzanian nursing training institutions are actively implementing PBL pedagogy [14]. The current study aimed at determining the effect of problem-based facilitatory pedagogy on motivation to learn among undergraduate nursing students in higher Tanzanian training institutions. The study was guided by specific objectives including determining the effect of the problem-based facilitatory pedagogy on the level of intrinsic motivation, extrinsic motivation, and Amotivation to learn among undergraduate nursing students in Tanzanian higher learning institutions.

The null hypothesis was used to determine the effect of the independent variable over the outcome variable, which stated: "there was no significant difference in the levels of motivation to learn between nursing students exposed to the problem based facilitatory pedagogy and their counterparts in the control group (lecture-based learning method) in Tanzanian higher learning institutions."

\section{Methods}

\section{Study design and approach}

A pre-post controlled quasi-experimental study design with a quantitative research approach. The study included consented undergraduate nursing students with steady class attendances. Recruitment of the study participants was done in early February 2018 before baseline data collection. A cluster-randomized educational institution via coin tossing (five hundred Tanzanian coins) was determined by the research assistants to allocate the sampled institutions into either be in an intervention or a control group. The Head of the coin was assigned to an intervention and the second side of the coin (with Buffalo image) to the control group. The researcher and research assistants did the tossing of the coin and identified the sides respectively.

Participants' social demographic and academic characteristics were used to match them to ensure their similarities at baseline. As it has been used by previous 
studies of the same methodological approaches [1, 4], WinPepi Software program version 11.65 was considered reliable to be used in this study. The ratio of sample size $(n=401)$ was B:A $=1: 2$ with 134 participants in the intervention and 267 participants in the control group of which a proportionate formula $\left(n i=P i \times \frac{P i}{n}\right)$ was used to determine participants' distribution at classroom levels. As shown in Table 1, participants in the intervention and those in the control group did the same pretest and post-test respectively. However, they were treated differently whereas participants in an intervention group learned the conflict resolution content using a problem-based facilitatory pedagogy while those exposed in the control group learned the same content using a lecture-based learning (LBL) method.

\section{Data collection process}

The researcher and research assistants identified the study participants in the sampled study centers and put them in a separate and quiet room to ensure privacy and confidentiality during the filling process of questionnaires. Brief instructions on how to fill the questionnaires were provided among the study participants before distributing copies of the questionnaires. The researcher and assistants supervised the process and responded to participants' queries throughout the process before collecting questionnaires. All participants answered the same questions before and after an intervention.

\section{Data collection tools}

The instrument used for data collection was a structured Questionnaire titled Academic Motivation Scale (AMSHS 28). A tool was adopted from AMS - College Version 1993 [24] having a Cronbach's Alpha of 0.84. It has once been validated by Haugan et al., [25] and used by Millanzi et al., [4] in Tanzania. The tool was used for assessing levels of intrinsic motivation (towards knowledge, accomplishments, and stimulation), extrinsic (introjected and identified regulation), and amotivation among undergraduate nursing students. The AMS-HS had 28 items with 140 scores on a 5-point point Likert scale. Scale $1=$ does not correspond at all, $2=$ correspond a little, $3=$ corresponds moderately, $4=$ corresponds a lot and $5=$ corresponds exactly. Part $\mathrm{A}$ of the instrument elicited information about demographic data of the study participants including their age, sex, education level, accommodation status, and marital status. Other important participants' characteristics included their interest status to join nursing, reasons to join it, their satisfaction status to nursing course, learning benefits, and learning difficulties they encountered during their learning processes. Part B elicited information about levels of motivation to learn adopted by students in their learning processes. This part covered three aspects (Intrinsic motivation, extrinsic motivation, and Amotivation to learn).

Intrinsic motivation was assessed by using a twelve [12] 5-point Likert ( $\geq 6$ scores were defined as intrinsically motivated) scale items, extrinsic motivation twelve [12] items ( $\geq 6$ scores were defined as extrinsically motivated), and Amotivation to learn 4 items ( $\geq 2$ scores were defined as intrinsically motivated). The overall motivation to learn among the study participants was then computed that had a cut-off point set at 70 scores from 140 total scores of the scale items. The study participant, who scored $\geq 70$ of the scale items, was defined as motivated to learn otherwise not.

\section{Development and prototyping of the research conflict resolution material in the nature of problem-based Facilitatory pedagogy design}

The process of developing and prototyping the PBL materials adopted the conceptualized framework that was developed by Mafumiko [26] but also used by Millanzi et al., [27]. As shown in Fig. 1, the development and prototyping procedures of conflict resolution material in the nature of problem-based facilitatory pedagogy followed four [4] phases including phase 0, I, II, and III. Phase 0 focused on reviewing various documents including online and off-line books, published scholarly nursing profession magazines, and other relevant materials. The reviewed materials made it possible for the development of draft " 0 " of the conflict resolution material (Prototype "0"). The developed draft was then shared with the experts including tutors/lecturers who had at least $>1$-year working experience in teaching leadership and management content and 1 expert in curriculum development for their professional and technical inputs, advice, and comments on the material.

Table 1 Summary of a Study Design

\begin{tabular}{lll}
\hline Activity & Intervention group & Control group \\
\hline Pre-test (Baseline) & $\sqrt{ }$ & $\sqrt{ }$ \\
Intervention (Mid-line) & Problem-based Facilitatory Pedagogy & Lecture-based Learning Method \\
Post-test (End-line) & $\sqrt{ }$ & $\sqrt{ }$ \\
\hline
\end{tabular}

Source: Researcher's Plan (2018) 


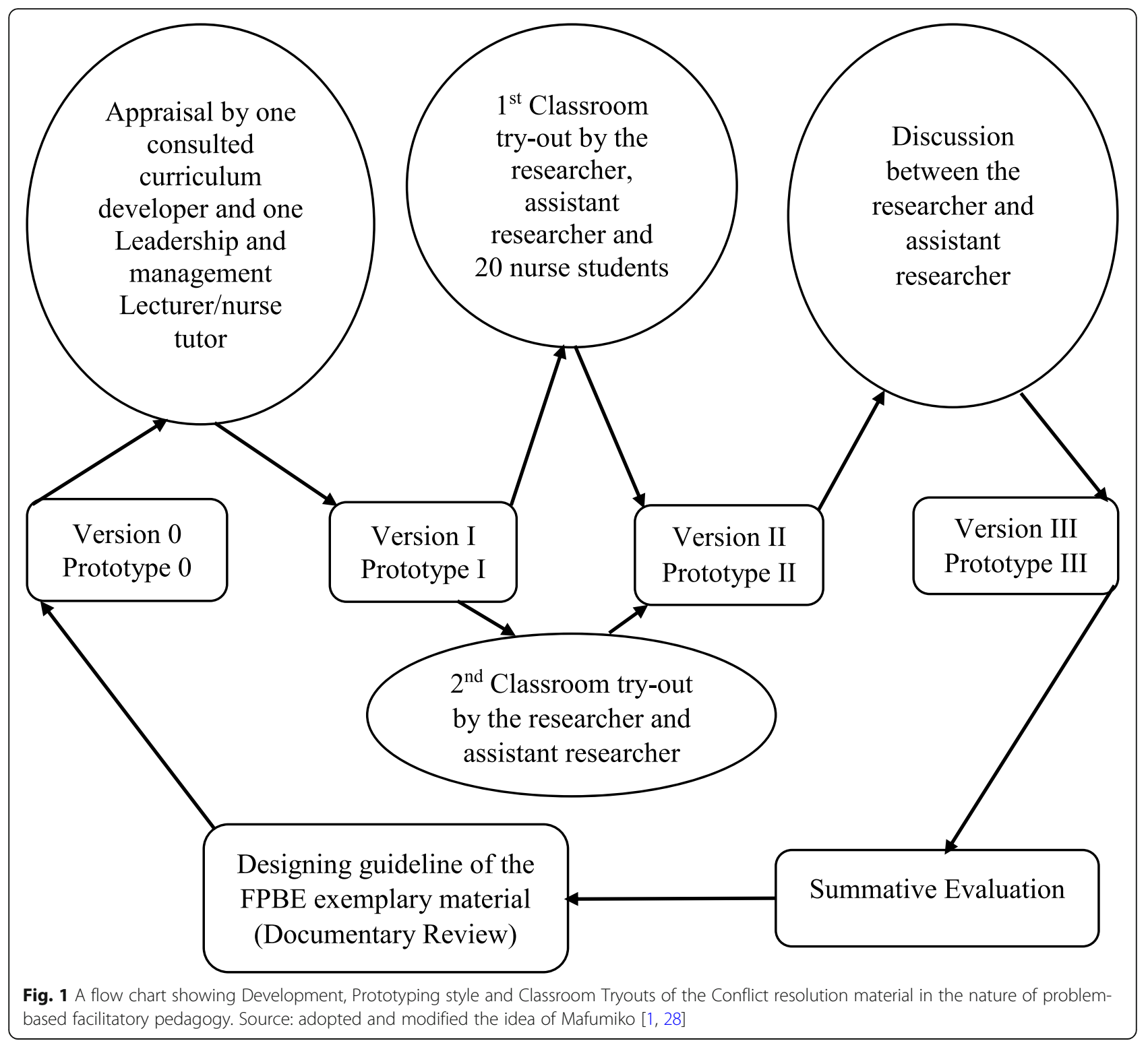

The revised version was exposed to phases "I", where a first classroom try-out among 20 nursing students, a principal investigator, 1 research assistant participated (Prototype "I"). Comments from experts in the first classroom try-outs were addressed accordingly and resulted in the second version, which was subjected to the second (phase II) classroom try-out (Prototype "II"). The researcher addressed the comments from the second classroom try-out whereas together with the assistant researcher discussed and amended the inputs. The third version (phase III) was refined and subjected to the actual field-testing (Prototype "III"). Summative evaluation of the effectiveness of PBL material on the learning process and the academic motivation was determined through a student's experiences inventory (SEI) developed by the researcher and the administration of posttest among nursing students.

\section{The intervention (problem-based Facilitatory teaching sessions)}

The intervention part adopted and modified the intervention flow pattern by Millanzi et al., [1] who implemented research of the same nature among nursing students in Tanzania. The intervention implementation involved aspects such as an introduction and formulation of groups, problem presentation, solving, discussions and sharing, scaffolding and group facilitation, mode of assessments, and summary of the study 
activities between an intervention and the control group.

Introduction and formulation of learning groups This was the first-day segment which was characterized by the introduction about the intervention process including descriptions of the objectives and the expected terminal behavior among students throughout in-out class learning activities. The researcher and assistants randomly assigned a maximum of 8 students in groups. Given a facilitator's guidance, members of the formed groups had to appoint a chairperson and secretary among themselves and other members were supposed to actively take part in the assigned activities.

Problem presentation, solving, discussions, and sharing Objectives of each session had to be reviewed by the researcher and assistants before their commencements. Classroom management and organization was assured through getting members in their group seat in the round to promote eye contact and enhance the easy flow of discussions through sessions. The developed paper-based conflicts-based scenario among nurses at working places was shared with each group. Debriefing of how to address them through learning activities was done by the researcher and assistants before allowing them to start addressing the assigned problems. Given a $30 \mathrm{~min}$, students were instructed to identify the professional context of the problem, listing what they knew, what they did not know, what they needed to know and establish the issues to learn from the problem.

Nevertheless, facilitators' roles were to guide students via clarifying, ranking, and assigning learning tasks to each member of the group that would enable them to find appropriate strategies to resolve problems. Within 60 to $120 \mathrm{~min}$, nursing students were guided to identify and suggest with reasons, the available resources needed to resolve the assigned scenario. Moreover, a period of 1 week was given among students to explore possible conflict resolution strategies that would be channeled to the scenario, then be shared and discussed in the entire class during the next scheduled session. As a closure of each session, nursing students were required to communicate to the researcher and or assistants either by mobile texts, orally or in writings through email whenever they need any help or clarifications of what was learned in the past sessions or what was to be learned in the next session. Following sessions after the offered week served as a room for students to present, discuss, and share what did with their colleagues in the entire class.

Scaffolding and group facilitations Facilitators of sessions were required to scaffold the learning areas that students could not manage by themselves and facilitate their learning activities by making the learning environment friendly to their learning activities i.e. Adequate supply of learning resources and material and enough space for them to discuss or move freely and without disturbances each other. Owing to the big class size, sometimes, facilitators of the sessions used group leaders to control and lead group members. However, a leader who was used had to be briefly instructed on how to act as facilitators during monitoring and controlling the learning activities among members in respective groups.

Mode of assessment Both, formative and summative assessments were used to assess nursing students' learning behaviors and session achievements. Peer assessment served as a formative assessment among students that helped to determine students' interactions and abilities to evaluate one another. To evaluate the course PBL material implementation, the facilitator administered a student's experience inventory (developed by a researcher) among randomly selected students after each session. Besides, the written posttest was used as a summative assessment to measure the end-line levels of academic motivation among nursing students.

\section{Summary of the study activities between an intervention} and the control group

Table 2 presents a flow plan of intervention with the session's implementation to the end-line data collection between the intervention and the control group (Table 2).

\section{Data analysis}

The study performed statistical analyses using the Statistical Product for Service Solutions (SPSS) version 23. Descriptive statistics through chi-square and crosstabulation established participants' socio-demographic profiles and determined the relationship between categorical variables. Binary and multinomial logistic regression analyses were performed to determine the association between variables. The confidence interval (CI) was set at $95 \%$ whereas the probability value of $\leq 0.05$ was considered to be statistically significant. The power of the study was set at $80 \%$ of demonstrating the effectiveness of an intervention.

\section{Results}

Demographic characteristics of the study participants

Findings in Table 3 show that $65.8 \%$ of the study participants were males. Almost $73.6 \%$ of the study participants had ages ranging between 25 and 29 years. Moreover, $69.3 \%$ of the study participants lived in-campus. No statistically significant difference was observed in their gender, age, and marital status distributions between groups $(p>0.05)$. However, a significant difference was observed 
Table 2 Summary of the study activities between an intervention and the control group $(n=401)$

\begin{abstract}
Intervention group
134 study participants recruited

Administered the AMS-HS questionnaires as a pre-test to establish baseline information

Participants organized in groups of 5 to 8 members

Each member of the formed group was assigned a role to play by himself or herself e.g. Chairperson, secretary, timekeeper, etc. and they exchanged the roles per each session activities

Participants were exposed to two sessions lasting for 90 min each per week according to the institutional schedule. 5 min were reserved for a break and 10 min for a facilitator to summarize the learned topic and respond to students' queries per each session
\end{abstract}

Exposed to nursing-based conflict resolution content through problem-based facilitatory pedagogy

Participants in their respective groups were exposed to conflict scenario to study and find appropriate strategies to resolve it

A representative from each group had to share and defend their work in front of the entire class

Participants in their respective groups were required to present and defend a homework activity of the previous session in the entire classroom before the commencement of another day's session

Participants were required to note-keep (establish records) of what is learned and performed per each session so that they could develop a summary of session activities by the end of all sessions

Two to three randomly selected participants had to share their experiences of the session activities, time, content dosage, and their opportunities to learn

Administered the AMS-HS questionnaires as post-test to establish baseline information

Source: Researcher's plan (2018)

Table 3 Demographic characteristics of the study participants between the Intervention and Control group $(n=401)$

\begin{tabular}{llll}
\hline Variable & Intervention & Control & P-value \\
\hline Sex & $\mathbf{n}(\%)$ & $\mathbf{n}(\%)$ & \\
Males & $83(61.9 \%)$ & $181(67.8 \%)$ & 0.244 \\
Females & $51(38.1 \%)$ & $86(32.2 \%)$ & \\
Age & & & 0.192 \\
$<24$ yrs. & $6(4.5 \%)$ & $25(9.4 \%)$ & \\
$25-29 y r s$. & $100(74.6 \%)$ & $195(73.0 \%)$ & \\
$>30 y r s$. & $28(20.9 \%)$ & $47(17.6 \%)$ & 0.695 \\
Marital status & & & \\
Single & $123(91.8 \%)$ & $248(92.9 \%)$ & 0.001 \\
Married & $11(8.2 \%)$ & $19(7.1 \%)$ & \\
In campus & & $235(88.0 \%)$ & \\
Yes & $43(32.1 \%)$ & $32(12.0 \%)$ & \\
No & $91(67.9 \%)$ & &
\end{tabular}

Source: Field Data (2019)

\section{Control group}

267 study participants recruited

Administered the AMS-HS questionnaires as a pre-test to establish baseline information

Participants were not organized into groups

Participants were not assigned in groups and thus had no roles to play alternatively

Participants were exposed to two sessions lasting for 90 min each per week according to the institutional schedule. 5 min were reserved for a break per each session. No summary of the learned topic and respond to students' queries from the facilitator per each session. "THANK YOU FOR YOUR ATTENTION" was the end sentence from the facilitator per each session

Exposed to nursing-based conflict resolution content through lecture-based learning pedagogy

Participants learned nursing-base conflicts at working place through facilitator-led PowerPoint presentations, question and answers, buzzing

Participants had opportunities to ask and answer questions from the facilitator

Participants were required to answer questions from the facilitator about the previous session before the commencement of another day's session

Participants had no opportunity. They just write summaries of what they learned for their read.

Participants had no such opportunity. They had to disport once the session is over.

Administered the AMS-HS questionnaires as post-test to establish baseline information

in the accommodation status of the participants between the two groups $(p<0.01)$ (Table 3$)$.

\section{Other important participants' characteristics (interest, reasons, satisfaction, learning benefits, and learning difficulties), which could influence motivation to learn} As shown in Tables 4, 73.8\% of the study participants were interested to join the nursing profession and its programs while $52.4 \%$ of a sample chose nursing programs, as their first "own choice". However, almost $20.9 \%$ of the study participants chose due to parent's/peer pressure. Moreover, findings revealed that $75.3 \%$ of the participants were satisfied with nursing courses being taught to them whereas, $84.0 \%$ of them agreed that the teaching and learning practices were of a benefit to their academic achievements and career path. Nevertheless, $30.7 \%$ of the study participants reported that they experienced some difficulties in comprehending course contents due to their complexity, while $25.9 \%$ of a sample 
Table 4 Distributions of other important participants' characteristics which were believed to influence academic motivation between the Intervention and Control group $(n=401)$

\begin{tabular}{|c|c|c|c|}
\hline Variable & $\begin{array}{l}\text { Intervention } \\
n(\%)\end{array}$ & $\begin{array}{l}\text { Control } \\
n(\%)\end{array}$ & $\begin{array}{l}X^{2} \\
P \text {-value }\end{array}$ \\
\hline \multicolumn{4}{|l|}{ Interest } \\
\hline Yes & $92(68.7 \%)$ & $204(76.4 \%)$ & $x^{2}=2.771^{a}$ \\
\hline No & $42(31.3 \%)$ & $63(23.6 \%)$ & 0.096 \\
\hline \multicolumn{4}{|l|}{ Reasons to choose nurse } \\
\hline Own choice & 71 (53.0\%) & $139(52.1 \%)$ & \\
\hline Parent's/peer pressure & $29(21.6 \%)$ & $55(20.6 \%)$ & $x^{2}=0.430^{a}$ \\
\hline Easier to get a job & $24(17.9 \%)$ & $48(18.0 \%)$ & 0.934 \\
\hline Entry qualifications & $10(7.5 \%)$ & $25(9.4 \%)$ & \\
\hline \multicolumn{4}{|l|}{ Satisfaction } \\
\hline Yes & 78 (58.2\%) & $224(83.9 \%)$ & $x^{2}=31.60^{a}$ \\
\hline No & $56(41.8 \%)$ & $43(16.1 \%)$ & 0.001 \\
\hline \multicolumn{4}{|l|}{ Learning benefits } \\
\hline Agreed & $104(77.6 \%)$ & $233(87.3 \%)$ & $x^{2}=6.200^{a}$ \\
\hline Disagreed & $30(22.4 \%)$ & $34(12.7 \%)$ & 0.013 \\
\hline \multicolumn{4}{|l|}{ Learning difficulties } \\
\hline Difficult accessing updated learning materials & $24(17.9 \%)$ & $56(21.0 \%)$ & \\
\hline Complex course contents & $49(36.6 \%)$ & $74(27.7 \%)$ & $x^{2}=9.665^{a}$ \\
\hline Inadequate support from lecturers & $18(13.4 \%)$ & 37 (13.9\%) & 0.046 \\
\hline Limited time & $25(18.7 \%)$ & 79 (29.6\%) & \\
\hline No conducive environment & $18(13.4 \%)$ & $21(7.9 \%)$ & \\
\hline
\end{tabular}

Source: Field Data (2019)

reported experiencing limited time to comprehend the course contents taught and participants who experienced difficulties in accessing learning materials constituted of $20.0 \%$. Other findings were found as shown in the table (Table 4).

\section{Overall levels of motivation to learn and its subscales among nursing students}

Findings of the levels of motivation to learn among nursing students were presented based on the overall motivation and its domains including intrinsic motivation (knowing what to learn, an accomplishment of learning tasks, and experiencing stimulation to learn),

Table 5 Overall Levels of Motivation to Learn and its Subscales among Nursing Students $(n=401)$

\begin{tabular}{lll}
\hline Variable & $\begin{array}{l}\text { Pre-test } \\
\text { n(\%) }\end{array}$ & $\begin{array}{l}\text { Posttest } \\
\boldsymbol{n ( \% )}\end{array}$ \\
\hline Overall Motivation to Learn & $140(34.9 \%)$ & $282(70.3 \%)$ \\
Intrinsic Motivation to Learn & $103(25.7 \%)$ & $289(74.3 \%)$ \\
Extrinsic Motivation to Learn & $143(35.7 \%)$ & $258(64.3 \%)$ \\
Amotivation to Learn & $257(64.0 \%)$ & $144(36.0 \%)$
\end{tabular}

Source: Field Data (2019) extrinsic motivation (identification of what to learn, introjection to learn, and regulation of motivation to learn), and amotivation to learn. The posttest findings in Table 5 indicate that $70.3 \%(n=282)$ of the study participants demonstrated motivation to learn contrary to $34.9 \% \quad(n=140)$ at baseline. Additionally, there was a statistically significant gain of posttest motivation to learn among nursing students between motivation subscales of which $74.3 \%(n=289)$ of participants demonstrated intrinsic motivation to learn. On the other hand, findings demonstrated that $64.3 \%$ $(n=258)$ of the study participants demonstrated extrinsic motivation to learn whereas $36.0 \% \quad(n=144)$ participants demonstrated amotivation to learn when assessed at post-intervention (Table 5).

\section{Factors related to the effect of an intervention on the} overall motivation to learn, among undergraduate nursing students between groups

Chi-square test and cross-tabulation findings in Table 6 point out that out of $282(70.3 \%)$ of the study participants who were motivated to learn, $95.5 \%$ $(n=128)$ were those exposed in the intervention 
Table 6 Factors related to and the effect of Intervention on the overall Motivation to Learn among undergraduate nursing students between groups $(n=401)$

\begin{tabular}{|c|c|c|c|}
\hline \multirow[t]{3}{*}{ Variables } & \multicolumn{2}{|c|}{ Motivation to Learn } & \multirow{3}{*}{$\begin{array}{l}X^{2} \\
P \text {-value }\end{array}$} \\
\hline & Yes & No & \\
\hline & $n(\%)$ & $n(\%)$ & \\
\hline \multicolumn{4}{|l|}{ Groups } \\
\hline Intervention & $128(95.5 \%)$ & $6(0.5 \%)$ & $x^{2}=7.041^{a}$ \\
\hline Control & $154(57.0 \%)$ & $116(43.0 \%)$ & 0.008 \\
\hline \multicolumn{4}{|l|}{ Gender } \\
\hline Males & $202(67.6 \%)$ & $62(60.8 \%)$ & $x^{2}=1.552^{\mathrm{a}}$ \\
\hline Females & 97 (32.4\%) & 40 (39.2\%) & 0.213 \\
\hline \multicolumn{4}{|l|}{ Age } \\
\hline$<24$ Yrs. & $20(6.7 \%)$ & $11(10.8 \%)$ & \\
\hline $25-30$ Yrs. & $220(73.6 \%)$ & 75 (73.5\%) & $x^{2}=2.316^{a}$ \\
\hline$>30$ Yrs. & $59(19.7 \%)$ & $16(15.7 \%)$ & 0.314 \\
\hline \multicolumn{4}{|l|}{ Marital status } \\
\hline Singles & $278(93.0 \%)$ & $93(91.2 \%)$ & $x^{2}=0.356^{a}$ \\
\hline Married & $21(7.0 \%)$ & $9(8.8 \%)$ & 0.551 \\
\hline \multicolumn{4}{|l|}{ Accommodation status } \\
\hline In campus & $209(69.9 \%)$ & $69(67.6 \%)$ & $x^{2}=11.421^{a}$ \\
\hline Off-campus & $90(30.1 \%)$ & $33(32.4 \%)$ & 0.023 \\
\hline \multicolumn{4}{|l|}{ Interest } \\
\hline Yes & $223(74.6 \%)$ & $73(71.6 \%)$ & $x^{2}=0.357^{a}$ \\
\hline No & 76 (25.4\%) & 29 (28.4\%) & 0.550 \\
\hline \multicolumn{4}{|l|}{ Satisfaction } \\
\hline Yes & $227(75.9 \%)$ & 75 (73.5\%) & $x^{2}=0.234^{a}$ \\
\hline No & $72(24.1 \%)$ & 27 (26.5\%) & 0.629 \\
\hline \multicolumn{4}{|l|}{ Reasons for choosing to nurse as a career } \\
\hline Own choice & $162(54.2 \%)$ & $48(47.1 \%)$ & \\
\hline Parents/peer pressure & $52(17.4 \%)$ & $32(31.4 \%)$ & $x^{2}=9.903^{a}$ \\
\hline Easier to get a job & $59(19.7 \%)$ & $13(12.7 \%)$ & 0.019 \\
\hline Entry qualifications & $26(8.7 \%)$ & $9(8.8 \%)$ & \\
\hline \multicolumn{4}{|l|}{ Learning difficulties } \\
\hline Inadequate and difficulty in accessing updated learning materials & $61(20.4 \%)$ & $19(18.6 \%)$ & \\
\hline Complex course contents & $92(30.8 \%)$ & $31(30.4 \%)$ & $x^{2}=1.209^{a}$ \\
\hline Inadequate support from lecturers & $43(14.4 \%)$ & $12(11.8 \%)$ & 0.877 \\
\hline Limited time & $76(25.4 \%)$ & $28(27.5 \%)$ & \\
\hline No conducive environment & $27(9.0 \%)$ & $12(11.8 \%)$ & \\
\hline
\end{tabular}

Source: Field Data (2019)

against $57.0 \%(n=154)$ participants in the control group. It was found that an intervention (Problembased facilitatory) pedagogy $\left(\chi^{2}=7.041^{\mathrm{a}}, p<0.01\right)$, accommodation $\left(\chi^{2}=11.421^{\mathrm{a},} p<0.01\right)$, and the reasons which made students join nursing programs $\left(\chi^{2}=\right.$ $\left.9.903^{\mathrm{a}}, p<0.05\right)$ were significantly related to the overall motivation to learn among nursing students respectively. Other variables did not show a statistically significant relationship with the outcome variable as shown in the table (Table 6).

The effect of an intervention on the overall motivation to learn among undergraduate nursing students between groups

Binary and multinomial logistic regression was done to determine the extent to which the intervention and the 
Table 7 Binary, and multinomial logistic regression to determine the effect of an Intervention on Motivation to Learn among undergraduate nursing students, between groups $(n=401)$

\begin{tabular}{|c|c|c|c|c|c|c|c|c|}
\hline \multirow[t]{2}{*}{ Variables } & \multirow[t]{2}{*}{ OR } & \multicolumn{2}{|c|}{$95 \% \mathrm{Cl}$} & \multirow[t]{2}{*}{ P-value } & \multirow[t]{2}{*}{$A O R$} & \multicolumn{2}{|c|}{$95 \% \mathrm{Cl}$} & \multirow[t]{2}{*}{$P$-value } \\
\hline & & Low & Upper & & & Low & Upper & \\
\hline \multicolumn{9}{|l|}{ Groups } \\
\hline Intervention & 1.729 & 1.130 & 2.646 & 0.012 & 1.720 & 1.122 & 2.635 & 0.013 \\
\hline \multicolumn{9}{|l|}{ Control (Ref) } \\
\hline \multicolumn{9}{|l|}{ Accommodation } \\
\hline In campus & 0.472 & 0.3 .4 & 0.732 & 0.001 & 0.591 & 0.349 & 1.002 & 0.051 \\
\hline \multicolumn{9}{|l|}{ Off-campus (Ref) } \\
\hline \multicolumn{9}{|c|}{ Reasons for choosing to nurse as a career } \\
\hline Own choice & 1.168 & 0.513 & 2.662 & 0.711 & 1.214 & 0.528 & 2.787 & 0.648 \\
\hline Parents/peer pressure & 0.562 & 0.234 & .1 .352 & 0.198 & 0.578 & 0.239 & 1.402 & 0.225 \\
\hline Easier to get a job & 1.571 & 0.597 & 4.132 & 0.360 & 1.635 & 0.616 & 4.337 & 0.324 \\
\hline Entry qualification (Ref) & $0^{\mathrm{b}}$ & . & & & & . & & . \\
\hline
\end{tabular}

Source: Field Data (2019)

reasons that made nursing students join nursing programs had in motivating them to learn. Findings in Table 7 indicate that participants in an intervention group were 1.720 (AOR) times more likely to be motivated to learn against participants in the control counterparts $(p<0.05$, CI: $1.122,2.635)$. On the other hand, participants who were living on the campus were 0.591 (AOR) times less likely to be extrinsically motivated than the participants who were living out campus $(p>0.05$, CI: $0.349,1.002)$. However, the reasons that made nursing students join nursing programs did not influence motivating students to learn when adjusted to other variables $(p>0.05)$ (Table 7).

\section{Discussion \\ Socio-demographic characteristics of the study participants}

The current study noticed many male students (65.8\%) joined the nursing program as their first choice compared to females. It is interesting to note that the observed finding was one of the successes the nursing profession is earning in its transition from the past, present, and future. The findings imply that males are currently motivated to join the nursing program as compared to the past where female nursing students were many. However, these findings do not line up with those found by Kusumawaty, Kumara, Emilia \& Haryanti [29] and Sabzevari, Abbaszade \& Borhani [30], that showed a majority of females selected to join nursing as their priority than males. The mismatch of findings between the two studies would probably due to many of the previous studies were done a long time ago than the current study, which was conducted within the expansion of the nursing profession position and market in the globe.
Nevertheless, the day-to-day awareness creation interventions and programs about the nursing profession and its career paths through various media could contribute to the variation of findings between the two studies above. Its advanced roles among nurses, the breakthrough of a persisted myth that nursing was for females and the need for more educated and qualified nursing professionals, and its potential contribution to the individual and community well-being have currently attracted more people to join it including males. It is worth to observe both females and males select nursing as their pathway to advance their educational and professional careers, for the sake of serving the community. On the other hand, it was worth it too to observe a great number of men joining the nursing profession as this would clear out the belief, which has existed for a long time that nursing was for females.

\section{Overall motivation to learn and its subscales among undergraduate nursing students}

Based on the findings presented above, it has been observed that with the control of other factors, problembased facilitatory pedagogy was a predictive factor in enhancing motivation to learn among nursing students. Nursing students would demonstrate the ability to know what to learn, accomplish the learning activities, and experience stimulation to learn more and more. Students exposed to the intervention-demonstrated pleasure to learn as they felt that teamwork and being occupied with learning tasks during, after sessions were very important, and could contribute something to their academic progress.

On the other hand, extrinsic motivation is an aspect that defines the ways students are motivated to learn through the influence of external stimuli such as 
environments, peer pressures, punishments, and rewards were also studied. Nursing students who were exposed to the problem-based facilitatory pedagogy were less times likely to be extrinsically motivated to their learning process as compared to their counterparts under the lecture-based learning pedagogies who demonstrated motivation to learn in the presence of external stimuli commonly for being recognized, rewarded, and to be identified by their colleagues that they know.

Contrary to the effect of an intervention on motivation to learn among nursing students, is well accommodated by the training institutions, and individual student's reasons to join nursing programs were found to be protective factors for them to be motivated to learn. The status of extrinsic motivation was also observed among nursing students who were living $\mathrm{n}$ campus. They were noted to be less times likely to develop extrinsic motivation to learn against students who were living off-campus. The majority of nursing students in the control group demonstrated to be motivated to learn just for being identified or recognized by others that they were able to know and solve issues. They demonstrated abilities to adopt values or attitudes they were impressed with for other famous or intelligent people for them to be accepted by others in their learning process. Moreover, nursing students in the control group were highly motivated to learn owing to the institutional regulations, principles, order, or rules.

Amotivation to learn among nursing students was measured to determine what discouraged them to learn. Findings demonstrated that participants who were exposed to problem-based facilitatory pedagogy were less likely demotivated in their learning processes as compared to their counterparts in the lecture-based learning pedagogies. The finding implied that the effect of the intervention and its associated setups and operationalization was significant than the lecture-based learning approach. Motivation has always been the central issue in nursing education and even being referred to as the most complex and challenging issue, facing educators, and students today. Various teaching modalities are tested in different settings and programs to help motivate students to learn with minimal support from educators.

Tallying with the findings of this study, Gaber et al, [10] found that if well structured, problem-based learning could enhance learning force within a student. An internal force to learn within an individual was observed in their study to be potential in influencing and directing behavior and willingness among students to put efforts into achieving a goal or reward through decreasing their tension caused by their social and academic needs. Based on these facts, the researcher observed that problembased teaching and learning pedagogy could positively make nursing students intrinsically motivated to learn and thus, become autonomous learners.

Moreover, the findings of this study are not new as they link with those found by Khamoushi et al., [8], which revealed low academic achievements of undergraduate nursing students, to be attributed to the type of teaching pedagogies that educators used. The more the didactic teaching methods were used, the more students were demotivated to their learning process when compared to the usage of constructive teaching pedagogies. They then concluded that there was a necessity to respond to the gap appropriately to improve student's academic achievements.

\section{Limitation of the study}

During the implementation phase of this study, group leaders were trained to act as facilitators. This would affect their full participation during in-out classroom activities, solving the presented problems in particular. Using group leaders would even make their colleagues not to take into serious their learning roles. The use of a quasi-experimental study design would influence selection bias among the study participants as it lacks randomization procedures. Lack of randomization procedures would make it difficult representation and generalizability the study findings.

\section{Conclusions}

This study builds on and extends the earlier research findings on the effects of problem-based facilitatory teaching and learning processes. The findings of this study demonstrate that a pedagogical innovation in the nature of collaborative learning from a problem-based facilitatory pedagogy among nursing students promises to improve their motivation to learn than the predominantly use of lecture-based learning approaches. The effect of problem-based facilitatory teaching and learning pedagogy provided opportunities for self-directed and peer group learning interactions among nursing students. The opportunities empowered students to the level that they were able to view and share learning pathways among themselves without fear or feeling shy. This was done through the vantage point of problem identification that enabled them to propose learning issues, practice knowledge research and sharing, and then revisit the scenario to solve problems.

The findings indicate that problem-based teaching and learning pedagogy can positively influence the levels of intrinsic motivation to learn among students. The elements of the problem-based facilitatory pedagogy, which were used in the current study, have the potential contributions to the development of competent graduate nurses. The study concludes that the implementation of problem-based facilitatory pedagogy is feasible and 
practical in Tanzanian perspectives. It appears to be worth considering integrating and implementing it in the nursing curriculum to enhance a formal shift from the use of traditional teaching and learning approaches and try modern participatory ones to make nursing students intrinsically motivated to learn nursing programs.

\section{Abbreviations \\ AM: Amotivation; Al: Auditing Inventory; AMS: Academic Motivation Scale; AOR: Adjusted Odds Ratio; Cl: Confidence interval; EM: Extrinsic Motivation; EMI: Extrinsic Motivation Identified; EMIT: Extrinsic Motivation Introjected; ETR: Extrinsic Motivation external Regulation; FPBE: Facilitation in a Problem Based Environment; IM: Intrinsic Motivation; IMC: Intrinsic Motivation towards Accomplishment; IMK: Intrinsic Motivation to Know; IMS: Intrinsic Motivation to experience Stimulation; IRRC: Institutional Research Review Committee; PBL: Problem-based learning; PhD: Doctor of Philosophy; QMLS N: Questionnaires on Motivation to Learn Strategies in Nursing; SD: Standard Deviation; SEl: Student's Experience Inventory; SPSS: Statistical Product for Service Solutions; UDOM: The University of Dodoma; WHO: World Health Organization}

\section{Acknowledgements}

Dr. Stephen M. Kibusi (PhD), supervisor, All staff and undergraduate nursing students from the St. John's University of Tanzania, staff, and students of the University of Dodoma, College of Health Science and College of Informatics library staffs, at the University of Dodoma'.

\section{Authors' contributions}

W. M designed and developed the proposal, exemplary research teaching materials, S.M.K. reviewed, shaped the research idea/concept, appraised the research teaching materials and research tools, and edited this article. All authors have read and approved this manuscript.

\section{Funding}

This research did not receive any specific grant from funding agencies in the public, commercial, or non-profit sectors'. It was privately sponsored.

\section{Availability of data and materials}

Data are available on request at walter.millanzi@udom.ac.tz or wcleo87@gmail.com because further analysis of other variables are being processed.

\section{Ethics approval and consent to participate}

All study participants in the current study were asked for informed consent for their participation.' The researcher and assistants obtained written informed consent from each participant as one of the criteria for them to join the study. The study was approved by the University of Dodoma (UDOM) Institutional Research Review Committee (IRRC)', Ethics Clearance to reach higher Training Institutions: approved by Principals and deans of the respective institutions/schools.

\section{Consent for publication}

Not applicable'

\section{Competing interests}

None'.

Received: 25 February 2020 Accepted: 25 November 2020

Published online: 04 January 2021

\section{References}

1. Millanzi WC, Kibusi SM. Exploring the effect of problem-based facilitatory teaching approach on metacognition in nursing education: a quasiexperimental study of nurse students in Tanzania. Nurs Open. 2020;7(April): 1431-45. Available from. https://doi.org/10.1002/nop2.514.

2. Bernardino A de O, Coriolano-Marinus MW de L, Santos AH da S, Linhares FMP, Cavalcanti AMT de S, de Lima LS. The motivation of nursing students and their influence in the teaching-learning process. Texto e Context Enferm 2018;27(1):1-10.
3. Natarajan J, Muliira JK, van der Colff J. Incidence and perception of nursing students' academic incivility in Oman. BMC Nurs. 2017;16(1):1-9.

4. Millanzi W, Kibusi S. Effect of Facilitation in a Problem-Based Environment on the Meta-Cognition and Learning Motivation in Nursing: A QuasiExperimental Study Among Nurse Students in Tanzania. SSRN Electron J [Internet]. 2018 [cited 2019 Apr 23]; Available from: https://www.ssrn.com/ abstract $=3153544$

5. Oksuz GS\& E. Academic motivations and academic self-efficacy of nursing students. J Clin Anal Med. 2017;8(1):47-51.

6. Duiker LP. An Analysis of the Selection Criteria and Processes into Basic Nursing Diploma Programme in the Gauteng Province, South Africa. 2016; (February):1-97.

7. Carroll JW. Academic motivation of degree-seeking undergraduate students at a for-profit University in the United States; 2016.

8. Khamoushi F. Original article achievement and academic motivation among students of Kermanshah University of Medical Sciences in $2013{ }^{*}$. Educ Res Med Sci [Internet]. 2015;3(2):9-13 Available from: http://journals.kums.ac.ir/ ojs/.

9. Hassankhani H, Aghdam AM, Rahmani A, Mohammadpoorfard Z. The relationship between learning motivation and self-efficacy among nursing students. Res Dev Med Educ [Internet]. 2015;4(1):97-101 Available from: http://journals.tbzmed.ac.ir/rdme.

10. Gaber MA, Moustafa MS. The Development of motivational strategies for nursing students at Zagazig University in Egypt. J Nurs Educ Pract 19254059. 2015;5(6) Available from:. https://doi.org/10.5430/jnep.v5n6p62.

11. Gattinger H, Leino-Kilpi H, Hantikainen V, Köpke S, Ott S, Senn B. Assessing nursing staff's competencies in mobility support in nursing-home care : development and psychometric testing of the Kinaesthetics Competence ( KC ) observation instrument. BMC Nurs [Internet]. 2016:1-11. Available from: https://doi.org/10.1186/s12912-016-0185-z

12. Heid CL. Motivation and persistence among BSN students in Northeast Ohio: A correlational study. Diss Abstr Int Sect B Sci Eng [Internet]. 2016 76(8-B(E)): No-Specified. Available from: http://ovidsp.ovid.com/ovidweb.cgi? $T=J S \& P A G E=r e f e r e n c e \& D=p s y c 13 \& N E W S=N \& A N=2016-17340-095$.

13. Stichler JF, Fields W, Kim SC, Brown CE. Faculty knowledge, attitudes, and perceived barriers to teaching evidence-based nursing. J Prof Nurs. 2011; 27(2):92-100.

14. MOHSW. The United Republic of Tanzania Ministry of Health and social welfare: curriculum information for ordinary diploma Programme in nursing (NTA level 4-6). Dar es Salaam; 2008.

15. Makunja G. Challenges facing teachers in implementing competence-based curriculum in Tanzania : the case of community secondary schools in Morogoro municipality. Int J Educ Soc Sci [Internet]. 2016;3(5):30-7 Available from: www.ripknet.org

16. Kusurkar R, Croiset G, Kruitwagen $C$, ten Cate O. Validity evidence for the measurement of the strength of motivation for medical school. Adv Heal Sci Educ. 2011;16(2):183-95.

17. Jackson YM. An exploration of the effectiveness of problem- based learning in nursing education. 2016; Available from http://scholarworks.waldenu.edu/ dissertations.

18. Rhem J. Problem-Based Learning. ISSN 1057-2880 [Internet]. 2006:8(1):1-7. Available from: mhtml:http://netdev2.lerner.udel.edu:8080/serva/turkey/ Shared Documents/Supplemen...

19. Amoako-sakyi $\mathrm{D}$, Amonoo-kuofi H. Problem-based learning in resource-poor settings : lessons from a medical school in Ghana. BMC Med Educ [Internet]. 2015;15(221):1-8. Available from:. https://doi.org/10.1186/s12909-015-0501-4.

20. Vygotsky L. Vygotsky's Social Constructivists Theory of Learning. 1934. 5(2002)

21. Bishaw A, Egiziabher YG. Comparison of traditional and constructivist teaching approaches in using English language learning strategies; ( grade eleven students of Bahir Dar preparatory school ). Ethiop J Educ Sc [Internet]. 2013;9(1):1-13 Available from: https://www.ajol.info/index.php/ ejesc/article/view/104968.

22. Matthew-maich N, Martin L, Hammond C, Palma A, Pavkovic M, Health A et al. Nursing students ' perceptions of effective problem-based learning tutors, vol. 12; 2016. p. 48-59.

23. Campus BR, Azeem M, Road C. Constructivist Vs traditional : effective instructional approach in teacher education Abida Khalid. Int J Humanit Soc Sci [Internet]. 2012;2(5):170-7 Available from: www.ijhssnet.com.

24. Lucidi FA\& F. The Academic Motivation Scale ( AMS ): Factorial structure, Invariance, and Validity in the Italian Context. 2008;15(4):211-20. 
25. Støen Utvær BK, Haugan G. The academic motivation scale: dimensionality, reliability, and construct validity among vocational students. Nord J Vocat Educ Train. 2016;6(2):17-45.

26. Mafumiko FMS. The Potential of Micro-scale Chemistry Experimentation in enhancing teaching and learning of secondary chemistry: Experiences from Tanzania classrooms. NUE J Int Educ Coop [Internet]. 2008;3:63-79. Available from: file://L:Nisiting/The Potential of Micro-scale Chemistry Experimentation in enhancing teaching and learning of secondary chemistry.pdf.

27. Millanzi WC, Kibusi SM. Exploring the effect of problem-based facilitatory teaching approach on metacognition in nursing education: a quasiexperimental study of nurse students in Tanzania. Nurs open [internet]. 2020;2020(February):1-15. Available from. https://doi.org/10.1002/nop2.514

28. Mafumiko FMS. The Potential of Micro-scale Chemistry Experimentation in enhancing teaching and learning of secondary chemistry: Experiences from Tanzania Classrooms. NUE J Int Educ Coop, NUE J Int Educ Coop [Internet]. 2008 [cited 2017 Sep 5]; Available from: http://incet.naruto-u.ac.jp/drupal6/ sites/incet.naruto-u.ac.jp/files/journal_03_09.pdf.

29. Kusumawaty I, Kumara A, Emilia O, Haryanti F. Assessing the learning process of caring behavior among nursing students in Palembang, Indonesia. Glob J Med PUBLIC Heal 2277-9604 [Internet]. 2016;5(4). Available from: http://www.gimedph.com.

30. Sabzevari S, Abbaszade A, Borhani F. The Assessment Methods and Learning Approaches in Nursing Students of Kerman University of Medica Sciences in Iran 2013;4(2):160-164. Available from: http://www.scirp.org/ journal/ce.

\section{Publisher's Note}

Springer Nature remains neutral with regard to jurisdictional claims in published maps and institutional affiliations.

Ready to submit your research? Choose BMC and benefit from:

- fast, convenient online submission

- thorough peer review by experienced researchers in your field

- rapid publication on acceptance

- support for research data, including large and complex data types

- gold Open Access which fosters wider collaboration and increased citations

- maximum visibility for your research: over $100 \mathrm{M}$ website views per year

At $\mathrm{BMC}$, research is always in progress.

Learn more biomedcentral.com/submissions 